\title{
Políticas de EMPleo y RENTAS MíNIMAS
}

\author{
Mikel de la Fuente Lavín \\ Universidad del País Vasco
}

RESUMEN

El pensamiento económico neoliberal postula que el desarrollo excesivo del Estado de Bieneslar y particularmente la generosidad de prestaciones sociales tales como las de desempleo seria responsable de la agudización del desempleo y del incremento de su duración. Este estudio analiza estos principios ideológicos basados en un sofismo, porque ser empleado no sólo significa ganar importantes salarios sino también conseguir un estatus adecuado. El autor argumenta que las prestaciones por desempleo representan una protección contra los puestos de trabajo peor remunerados De acuerdo con estas ideas deben existir siempr dos elementos en cualquier política de desempleo: (1) una reducción en las boras de (rabajo, y (2) salarios minimos determinados por cada gobierno regional. En esta linea, la solución al desempleo está relacionada con una reducción del tiempo de trabajo y con un sistema de rentas minimas de inserción que baga posible un puesto de trabajo decente.

Palabras claves: Prestaciones por Desempleo, Pensamiento Neoliberal, Estado de Bienestar. Rentas minimas de inserción, reducción del tiempo de trabajo

ABstract:

One of the most important ideas of the modern Neo-liberal political program is the excessive growth of the Welfare State in western economies. We can specify this idea for example in the theories that explain that unemployment benefits policies tend to make unemployment less "expensive", and so the duration of unemployment grows.

This paper analyses these ideological principles that are based on a sophism. because to be employed not only means to earn proper wages but also to get a proper status. The author argues that unemployment benefits mean protection against jobs with low wages. According to these ideas there must always be 2 elements in any unemployment policy: (1) a reduction in the bours of work, and (2) minimum wages that are decided by each regional government. According to the ideas of the author the solution to unemployment is related to a reduction of the working bours and to a system of minimum wages and rents that make possible a decent job.

Key words: Unemployment benefits, Neoliberal Theory, Welfare State, Minimum wages and rents, reduction of working bours. 
I. INTRODUCCIÓN

El pensamiento económico neoliberal, basado en la llamada teoría neoclásica, postula que el desarrollo excesivo del Estado del Bienestar y particularmente la generosidad de prestaciones sociales tales como las de desempleo y las rentas mínimas de inserción, sería responsable de la agudización del desempleo, en especial de los trabajadores poco cualificados. La baja productividad de los mismos provocaría que, al sólo poder ser contratados con bajos salarios, encontrarían un "cómodo refugio" en estas prestaciones. Aunque -algunos- los defensores de este razonamiento reconozcan que el nivel de estas prestaciones no permite cubrir adecuadamente las necesidades elementales de sus perceptores, plantean que encierra a los mismos en "trampas del paro" (o "trampas de la pobreza") en la medida en que estas personas tendrían escaso interés en desarrollar un empleo debido a la escasa diferencia entre el ingreso mínimo garantizado y su salario. Este planteamiento tiende a obviar que el desempleo de masas corresponde a una carencia de empleos y no a comportamientos de la oferta de trabajo.

Los análisis internacionales ${ }^{1}$ han mostrado que para el conjunto de ocho países europeos estudiados "el $64 \%$ de los parados declaran que desearían trabajar de una forma u otra, incluso en la hipótesis en que no fuera para ellos necesario financieramente", porcentaje superior al que manifiestaban los que tenían empleo (el 48\%). Esta mayor voluntad de trabajar de los desempleados en relación con los empleados reflejaría que, en palabras de J. Gadrey, "el desempleo aumenta la toma de conciencia del valor del trabajo". La actitud de los parados es similar en el conjunto de los países estudiados, a pesar de las notables diferencias en los importes de las prestaciones de desempleo, lo que acreditaría que la motivación para la búsqueda de trabajo es independiente del nivel de protección de los desempleados y por tanto de la diferencia de remuneraciones entre los que tienen trabajo y los que no lo tienen. Esta encuesta expresa que el empleo no es solamente un salario, sino que es también un estatuto, una forma en la actualidad necesaria de identidad social y personal, que permite superar lo que R. Castel llama "desafiliación social"2.

1. Comunicación elaborada, a petición de la Comisión Europea, por D. Gallei y recogida por J. Gadrey en Liberation, de 19 de febrero de 2001, cuyos comentarios seguimos.

2. R. Castel, Les métamorphoses de la question sociales. Fayard, 1995, págs. 466-7. (traducción en castellano, Las metamorfosis de la cuestión social, Paidós, Buenos Aires, 1997). 
En España existen diferencias apreciables entre las retribuciones salariales mínimas y las prestaciones sociales. Las prestaciones de desempleo han conocido una evolución que amplifica las diferencias entre la prestación y el salario precedente ${ }^{3}$. Para los trabajadores que trabajen a tiempo completo el subsidio de desempleo o las RMI son inferiores al salario mínimo interprofesional y, más aún, a los salarios mínimos convencionales. La observación que insiste en la reducida magnitud de la diferencia entre el Salario Mínimo Interprofesional y las prestaciones sociales ${ }^{4}$, no tiene en cuenta que ese ingreso complementario de 20000 o 30000 ptas. puede permitir satisfacer, aunque sea precariamente, necesidades elementales. En todo caso, la elevación generalizada de las rentas de inserción sería un elemento de fijación de normas aceptables de empleo y salarios, en la medida en que permitiría a sus beneficiarios rechazar empleos que no les permiten vivir con un mínimo de dignidad.

El problema surge con el desarrollo del tiempo parcial mal remunerado (al SMI o poco más) que proporciona ingresos inferiores al SMI. Para algunos sectores (jóvenes) los contratos a tiempo parcial pueden ser el primer eslabón hacia empleos de más duración y mejor remunerados, pero para otros (adultos poco cualificados, especialmente mujeres), pueden constituir situaciones estables o que se alternen con el paro. Esta problemática conduce a la conveniencia de acabar con las situaciones involuntarias de tiempo parcial, mediante el establecimiento de fórmulas que establezcan el derecho de vuelta al tiempo completo. La regulación española sobre el tiempo parcial, contempla que las solicitudes de los trabajadores en la materia de conversión del tiempo a tiempo parcial a tiempo completo, deberán ser tenidos en consideración, "en la medida de lo posible, por el empresario" (art. 12.4.e ET), lo que "obliga a muy poco", como ha senalado Palomeque López, al estar basado el régimen de la institución no en un derecho del trabajador, sino en un acuerdo entre las partes ${ }^{5}$.

3. La Ley $22 / 1992$ reducía del $80 \%$ al $70 \%$ la prestación de los primeros 180 días de prestación. Posteriormente, una reducción menor se ha operado con la Ley $66 / 1997$, al excluir a las horas extraordinarias de la base reguladora de la prestación.

4. Las diferencias entre el SMI y el subsidio asistencial de desempleo ( $75 \%$ del SMI, excluida la parte proporcional de las pagas extraordinarias) asciende en el 2001 a 21000 ptas/mes y en relación con la media de las rentas minimas de inserción aproximadamente a 36000 ptas. mensuales (estimación realizada sobre la base de que en 1996 esa cuantía era ligeramente superior a la mitad del SMI y que las cuantías del subsidio y de las RMI hayan conocido una evolución similar). La cifra de 1996 se recoge por L. Ayala Cañón, "Las rentas mínimas en el Estado de Bienestar español", en R. Muñoz de Bustillo (Ed.), El Estado de Bienestar en el cambio de siglo, Alianza Editorial, 2000, pág. 341.

5. M.C. Palomeque López, "El <nuevo> contrato de trabajo a tiempo parcial", en AA.VV (M. E. CASAS BAAMONDE y F. VALDÉS DAL-RÉ, Coords.), Los contratos de trabajo a tiempo parcial, Lex Nova, Valladolid, 2000, pág. 57. 
La teoría de la "trampa del paro" es utilizada por el pensamiento neoliberal como un argumento suplementario para una pretensión antigua y constante: la necesidad de que los trabajadores acepten la reducción de los salarios para favorecer el empleo. Ya hemos expuesto en el apartado que los salarios más bajos no aumentan el empleo. Pero no está de más señalar que el salario además de un coste de producción para el empleador representa un ingreso, en muchos casos el único, para el asalariado. Desde este punto de vista la delimitación temporal pertinente no es la unidad de tiempo trabajada, día u hora, sino la que relaciona el salario con la duración de la existencia (el mes, el año...). En este sentido, los cambios en las condiciones de empleo, con el desarrollo de la contratación temporal y a tiempo parcial, están en la base de lo que se ha calificado como pobreza asalariada (los working poor) ${ }^{6}$.

La primera parte de este trabajo, tras examinar la situación y raíces del desempleo en Europa, se enumeran las características de las políticas de empleo, deteniéndose en el análisis de la reducción del tiempo de trabajo en la medida que nos parece que es el instrumento más adecuado de combate contra el desempleo y la pobreza y la exclusión que se derivan del mismo. En la segunda parte, se examina brevemente el surgimiento y características de las Rentas Mínimas de Inserción autonómicas, especialmente la correspondiente la de la Comunidad Autónoma del País Vasco, y su necesaria integración con la política de empleo.

\section{Desempleo y politicas de empleo}

\section{El euro-desempleo}

La convicción subrayada en el Informe Supiot ${ }^{7}$, que comparto, según la cual "la reflexión sobre el devenir del trabajo en Europa debe inscribirse en la del futuro del empleo en Europa", justifica a mi entender, que previamente al análisis de la política comunitaria de empleo, se haga un breve comentario sobre la evolución del empleo en la Unión Europea, con una perspectiva temporal más amplia que la coyuntura favorable que se ha producido desde 1998.

Para el conjunto de la UE, el número de parados ha pasado de 12,3 a 17,1 millones entre 1990 y 1999 , mientras que la tasa de paro aumentaba del $8 \%$ al $10 \%$. Sea cual sea el indicador que se utilice, las marcas de los mercados de trabajo europeos parecen mediocres comparadas con las de Estados Unidos.

6. Según el Servicio de Estadística de la Comunidad Autónoma del País Vasco (EUSTAT), en el año 2000, los ingresos salariales de 117.238 personas ocupadas en esa Comunidad no alcanzaban el Salario Minimo Interprofesional.

7. A. Supiot (Coord.), Au-delà de l'emploi. Transformation du travail et devenir du droit du travail en Europe, Commision européenne, Documents de Recherche", 1999. pág. 93. (urad. en castellano en Tirant Lo Blanch, 1999. 
La tasa de paro ha progresado constantemente en la UE, hasta alcanzar un nivel ampliamente superior al de Estados Unidos. En el último período ha aumentado 3,1 puntos en la UE (y 2,8 en Japón) mientras que bajaba 0,8 puntos en Estados Unidos. La misma superioridad se observa desde el punto de vista de la creación de empleos. En el período 1990-1999 han aumentado rápidamente en Estados Unidos (1,3\%) de media cada año, mucho más rápidamente que en la UE (sólo el $0,6 \%$ anual). Esta superioridad no es nueva sino que ya existía en los períodos anteriores.

La tasa de empleo, que relaciona el empleo con la población activa en edad de trabajar (15-64 años), representa una medida global de la capacidad de una economía en crear empleos. Este indicador permite diferenciar a países que obtienen resultados comparables desde el punto de vista de la tasa de paro, pero unos mediante la creación de empleos y otros mediante la reducción de la población activa. Esta tasa ha progresado regularmente en Estados Unidos, hasta alcanzar un $74 \%$ en 1998 , mientras que la UE ha registrado una evolución inversa que la ha llevado a una tasa del $61,1 \%$ en $1998^{8}$.

La posición más extendida, tanto en el mundo académico como en el político, en materia de comparación de los niveles de empleo, se basa en la idea según la cual los países que crean más empleo, a igualdad del resto de condiciones, son aquellos que han conseguido implantar la moderación salarial más pronunciada. Es decir, cuanto más se frenen los salarios, más empleo se podrá conseguir. Sin embargo, no hay evidencias científicas incuestionables sobre la relación entre el paro y el costo del factor trabajo, ya que hay mecanismos que juegan en sentido inverso". Desde el punto de vista macroeconómico, la elevación de los salarios representa simultáneamente un incremento de la demanda, lo que favorece el empleo y un incremento del costo del trabajo, que al reducir los márgenes empresariales disminuiría la actividad. Dicho de otra forma, la evolución del empleo está correlacionada negativamente con el salario real de cada trabajador pero positivamente con la parte salarial sobre el conjunto de la economía (explicación keynesiana). No se puede saber anticipadamente cual de estos posibles efectos va a predominar, por lo que es necesario acudir a los datos y estudios empíricos.

Según estudios realizados durante los últimos años, un alza del 10\% del costo salarial supone de 0 a $1 \%$ de supresiones de empleos. Hasta hace poco, venía aceptándose que sólo para el empleo de los menores de 20 años la sensibilidad del salario mínimo sería mayor: un alza del 10\% engendraría reducciones de empleo del 1 al 3\%, pero

8. OCDE, Informe sobre el empleo 1999, OCDE, 1999, pág. 245.

9. Un buen resumen de la discusión teórica y empírica sobre las relaciones entre costo del trabajo y empleo en J. Gautié, Cô̂t du travail et emploi, Collection Repères, La Découverte, París, 1998. 
análisis realizados sobre series longitudinales americanas han hecho aparecer contrariamente efectos positivos sobre el empleo ${ }^{10}$. Después de haber defendido durante años que el salario mínimo es un freno para el empleo, en su informe anual sobre el empleo correspondiente a 1998, la OCDE ha expuesto que los empresarios, al acordar salarios superiores al nivel de equilibrio del mercado, pueden "estimular la productividad de los trabajadores, incitarles a mostrarse más dinámicos y reducir la rotación de los empleos". Más específicamente en relación con el salario mínimo, en el mismo informe se añade que "un salario mínimo legal puede contribuir a evitar que las remuneraciones caigan más debajo de un nivel socialmente aceptable", aunque, a fin de no ir demasiado lejos en la ruptura con los planteamientos tradicionales, mantiene la OCDE que es indispensable que su nivel sea poco elevado y no sea aplicable a los jóvenes ${ }^{11}$.

De la débil elasticidad del empleo con relación a su costo, resulta que son necesarias reducciones sustanciales del coste de la mano de obra para que se produzcan efectos significativos sobre el empleo, lo que implica que a los asalariados les resulta "muy cara" las creaciones de empleo basadas en las reducciones de salarios. Lo que si está demostrado es la correlación existente entre incremento de la tasa de beneficios (que equivale a reducción de la parte salarial) e incremento del desempleo: según datos de Eurostat, los países que han registrado los incrementos más altos de la tasa de paro en el conjunto de la UE, son aquellos que han experimentado la mayor moderación salarial. La retención de las ganancias de productividad a expensas de los salarios tenía por función restablecer las tasas de beneficio de las empresas. Sin embargo, el incremento de la tasa de beneficio no se ha traducido en un incremento de la inversión productiva y el empleo -el llamado teorema de Schmidt, antiguo Canciller de Alemania Federal-, sino en el aumento de los beneficios no invertidos, especialmente los de tipo financiero, cuya magnitud resulta de la diferencia entre las tasas de beneficio y de inversión.

Esta constatación concluye en un balance matizado. Por un lado, los mercados de trabajo de la UE han funcionado de forma poco eficaz en los últimos 20 años, puesto que no han permitido crear empleos en paralelo al crecimiento de la población activa, de forma que el paro ha progresado de forma generalizada. Pero, por otra parte, no es posible imputar estos malos resultados a las rigideces salariales puesto que la parte salarial ha retrocedido sensiblemente, sin por ello estimular el

10. M. Husson, A. Jolivert y C. Meilland, Performances d'emploi en Europe: les modalités du succès; Rapport pour le Conseil d'Analyse Economique, IRES, Junio de 1999, pág. 47.

11. Citas extraídas de C. Fouteau, "Le SMIC fait un tabac chez les Anglo-Saxons", Liásons SocialesMagazine, $n^{\circ} 137,1999$. Según la autora, tal cambio de posición se debe a estudios empíricos realizados en Estados Unidos (posiblemente el mismo al que se refiere la obra citada en la nota anterior) que concluyen en el reducido impacto del salario mínimo sobre el empleo y otro europeo que niega la relación causal en Europa entre las altas tasas de desempleo y el nivel elevado de los mínimos salariales. 
crecimiento y, aún menos, el empleo. El Comisario europeo del empleo, P. Flynn reconocía en 1997 está situación cuando declaraba en un encuentro con sindicalistas en Brighton que, "Europa es competitiva según todos los criterios económicos: tenemos un excedente comercial de más de 1\% del PIB; nuestra inflación es a la vez débil y estable; nuestra competitividad se mejora cada año el $2 \%$, o sea dos o tres veces más rápido que los EE.UU.; el costo unitario del trabajo está en disminución y la rentabilidad no ha sido nunca tan elevada clesde hace 35 años". Después de afirmar que los el gasto social constituye un factor productivo concluía que: "Nuestro verdadero problema es que nuestros éxitos en competitividad no han sido acompañados por la puesta en práctica de una política económica eficaz: nuestro paro persistente no es la consecuencia de políticas sociales sobredesarrolladas, es el resultado de políticas económicas subdesarrolladas y fragmentadas y de una falta de inversión en recursos humanos"12.

La referencia al desempleo en el conjunto de la UE no puede obviar que en su interior existen diferencias muy marcadas, por lo que procede preguntarse por sus razones. Es fácilmente constatable que en Europa el desempleo ha sido siempre superior en las regiones y Estados con mayores índices de desigualdad. En la actualidad, las tasas de desempleo son inferiores en los páses más igualitarios, en los que los salarios son más elevados y los sistemas de protección social están más desarrolla$\operatorname{dos}^{13}$. Conforme a las conclusiones de $M$. Husson ${ }^{14}$, las divergencias de los niveles de desempleo se deben fundamentalmente a las diferencias en el crecimiento económico. En los años ochenta estas divergencias podían conectarse a otros factores, básicamente a los ajustes en el mercado de trabajo a través del impacto de los mismos sobre el contenido en empleo del crecimiento y de su repercusión en la evolución de la población activa.

En los últimos años de los noventa se ha restablecido esa relación entre empleo y crecimiento. La desaceleración del crecimiento de la productividad está produciendo un "crecimiento más rico en empleos". Este fenómeno de recuperación de la conexión entre empleo y crecimiento, que se había perdido en la década de los ochenta, es común a la mayor parte de los países europeos. Sin embargo, como resultado de una desaceleración del crecimiento en relación con el periodo anterior, el empleo no ha alcanzado el ritmo de crecimiento de la fase expansiva anterior. El crecimiento del empleo de los últimos años se ha basado en una coyuntura muy favorable debida a causas tales como una caída de las tasas de interés, que han

12. Recogido de EUROINFO, Representación en Bélgica de la Comisión Europea (1997).

13. J. K. Galbraith, P. Conceiçao y P. Ferreira, "Desigualdad y desempleo en Europa: el remedio estadounidense", New Left Review, n 6, p. 45.

14 M. Husson, "¿Pourquoi les taux de chômage different en Europe". Revue de l'IRES, $\mathrm{n}^{\circ}$ 32, 2000, 45-79. LAN HARREMANAK, $\mathrm{n}^{\circ} 4$ (Universidad del País Vasco). 
alcanzado su nivel más bajo desde la Segunda Guerra Mundial y el auge del dólar que ha favorecido la actividad exportadora. El primero de estos factores está comenzando a resquebrajarse debido a la prioridad "anti-inflacionista" del Banco Central Europeo y su desprecio absoluto al drama del desempleo. En el caso español la temporalidad de la mayoría de las nuevas contrataciones y la reducción de las indemnizaciones por despido puede acabar con gran parte del empleo cuando aparezca un ciclo recesivo.

La cuestión que se plantea es si las diferencias en los ritmos de crecimiento, y en los niveles de empleo que les han acompañado, se deben a las reorganizaciones del mercado de trabajo de los ochenta, particularmente la moderación salarial que se produjo en ese período. Tras reconocer la legitimidad de la cuestión, Husson considera (basándose en investigaciones detalladas) que, ni los indicadores habituales de la flexibilidad del mercado de trabajo ni los indicadores de competitividad, explican los diferenciales de crecimiento. Su conclusión consiste en que los mejores resultados en empleo se han producido en los países caracterizados por una menor sustitución capital-trabajo ${ }^{15}$. Ese fenómeno producido en varios países europeos, en paralelo con los Estados Unidos, estaría compuesto por el efecto de las nuevas tecnologías y el compromiso social. Especialmente este último aspecto le parece decisivo y podría haber estado determinado por la reducción de la incertidumbre en cuanto a la evolución del salario real: habría reducido la conflictividad social y frenado la substitución capital-trabajo. Aceptando ese análisis, la prioridad europea de obtención de un importante grado de flexibilidad, habría sido doblemente negativa: por un lado, la excesiva moderación salarial habría reducido el crecimiento y con ello incrementado el desempleo, salvo en algunos pequeños países; y por otro lado, habría originado una excesiva substitución capital-trabajo, como resultado de una "sobre-reacción" en relación con la evolución de los costes salariales. A esto último habría contribuido la política monetaria de euro y monedas "fuertes".

El pensamiento neoliberal ha presentado la reducción de las prestaciones sociales y la privatización de las mismas como exigencias del crecimiento económico y la creación de empleo. Se presume que hay un conflicto entre la eficiencia económica y la equidad: la redistribución progresiva de la renta debida al incremento del gasto social, al afectar a la renta de las rentas más elevadas, estaría disminuyendo la capacidad de ahorro y con ello de inversión de las economías. Sin embargo, tales conclusiones no tienen base teórica ni empírica suficiente. V Navarro (1997, 46-53) ha examinado una amplia bibliografía que acredita que la mayor desigualdad no ha entrañado un crecimiento del empleo sino la extensión de la miseria. Las políticas neoliberales propias de Reagan y Thatcher, además de disminuir la equidad, supusie-

15. Esos países han sido Dinamarca, Irlanda, Noruega y Holanda. 
ron una reducción del ahorro, la inversión, un menor crecimiento de la productividad y del empleo ${ }^{16}$. Por el contrario, los paises con menos desigualdad han sido los que han experimentado un mayor crecimiento económico ${ }^{17}$.

\section{Alcance y carácter de la política de empleo}

Se entiende por política de empleo el conjunto de instrumentos específicos de los que se dotan los poderes públicos para mejorar la situación del empleo o atenuar algunas de las consecuencias del sub-empleo. Sin embargo, la delimitación precisa de la política de empleo es difícil de realizar, ya que a diferencia de otras materias de intervención de los poderes públicos, la política de empleo presenta contornos más difusos y constituye un conjunto más disperso. Además, otros aspectos de la política económica tienen repercusiones más importantes sobre el empleo que la política de empleo en sentido estricto. Así, la política monetaria de moneda fuerte que han asumido las autoridades nacionales y comunitarias han tenido una repercusión -negativa-más importante sobre el empleo europeo que las políticas estatales de empleo y su posterior comunitarización por el Tratado de Amsterdam.

Otro terreno problemático es la distinción entre la política de empleo con las políticas de asistencia destinadas a remediar las consecuencias de las carencias de empleo. El criterio utilizado suele ser la asignación a la política del empleo de las acciones que partan de las situaciones de no-empleo (y no de pobreza). Sin embargo, la frontera puede atenuarse, como ocurre con los contratos de inserción asociados a las rentas de inserción.

16. El mismo Banco Mundial reconoció en su informe de 1991 (p. 137), World Development Report, que "no existe evidencia de que el ahorro dependa de la desigualdad social. o que ésta conduzca a un mayor crecimiento económico. En realidad, la evidencia apunta a un sentido contrario, es decir, que mayor desigualdad lleva a menor crecimiento económico".

17. V. Navarro, Neoliberalismo y Estado del Bienestar, Ariel Económica, 1997, págs. 46-53.

Aspecto también señalado por J.M. González Páramo, "Gasto social y crecimiento económico en el Estado de Bienestar", Hacienda Püblica Española, Monografias n ${ }^{\circ} 2$ : El sector público español: una panorámica actual, 1994, pág. 150. J.M. González Páramo y G. López Casasnovas recogen asimismo la influencia positiva sobre el crecimiento económico no sólo de la inversión pública sino también del consumo público en sectores como educación y sanidad. Al argumento de que estos gastos de consumo se detraen de otros usos directamente productivos y en esa medida influyen negativamente sobre el crecimiento, responden que, en la medida en que los servicios públicos aumentan directamente el bienestar de los consumidores, la maximización del crecimiento a expensas de su reducción puede ser socialmente subóptimo Cfr., "El gasto público: problemas actuales y perspectivas", Papeles de Economia Española, n 69, 1996, (nota 14, pág. 34). .Esta es la posición que mantiene el Informe Supiot, cit., pág. 99 , cuando afirma que el grado elevado de inversión en capital humano de los países más ricos de la Comunidad, les permite una productividad de la población activa más elevada. 
Dentro de la política de empleo se pueden distinguir ${ }^{18}$ las políticas reguladoras del mercado de trabajo (condiciones de entrada, salida y modificación de las condiciones de empleo; del tiempo de trabajo: jornada, jubilaciones y prejubilaciones, tiempo parcial; proceso de determinación de los salarios: salarios mínimos, negociación colectiva, salarios en el sector público) y las llamadas políticas del mercado de trabajo dirigidas a mejorar la situación legal de los trabajadores. Estas últimas se subdividen entre políticas "activas" y "pasivas". La función de las políticas activas es la modificación de las condiciones de oferta y demanda sobre el mercado de trabajo con el objetivo de incrementar la tasa de salida del paro hacia la ocupación mediante medidas tales como la formación profesional, ocupacional y continua, las subvenciones a la creación de empleo o de apoyo a colectivos específicos (jóvenes, mujeres, discapacitados, parados de larga duración) y el desarrollo de servicios públicos empleo. Las políticas pasivas tienen por objetivo la compensación de ingresos a los privados de empleo mediante las prestaciones de desempleo y las prestaciones destinadas a los ceses anticipados de actividad (invalidez y prejubilación).

Durante la última década se ha desarrollado una orientación tendente a privilegiar las políticas "activas" partiendo de la idea de la conveniencia, por razones tanto económicas como sociales, de dedicar preferentemente los recursos a la inserción profesional de los parados más que al simple mantenimiento de sus ingresos. Sin embargo, de esa idea que en principio se podría compartir sin problemas, se han deducido consecuencias altamente discutibles: se ha presentado la reducción de la duración e intensidad de las prestaciones de desempleo como un elemento para "activar" a los parados; se han ampliado las causas de exclusión de las prestaciones... El resultado era presionar a los desempleados para que acepten cualquier empleo disponible. Otra alternativa, menos extendida sería considerar que prestaciones de duración e intensidad suficientes permiten que los parados dispongan de los medios y plazos adecuados para conseguir los empleos apropiados, especialmente en lo que se refiere a la correspondencia con sus cualificaciones. Obviamente la calidad de las prestaciones no supone que se obvie la puesta a disposición de los parados de medios tales como la formación, la ayuda a la búsqueda de empleo y otros.

\section{Las politicas de empleo en la UE}

A pesar del auge del desempleo en Europa durante los años ochenta, no es hasta diciembre de 1993 cuando el empleo aparece como una preocupación europea con la presentación en el Consejo de Bruselas del Libro Blanco Crecimiento, competitividad

18. Vìd., J.F. Jimeno, "Las políticas de empleo: pasado, presente y futuro", en J.A. Garde (Ed.), Políticas sociales y Estado de Bienestar en España. Informe 1999, Fundación Hogar del Empleado-Ed. Trotta, 1999, págs. 313 y ss. 
y empleo (Informe Delors). El Libro Blanco proponía continuar la política macroeconómica de reducción progresiva de los déficits públicos y políticas monetarias estables con el objetivo de una baja inflación. En el terreno específico del empleo recogía como prioridades la apuesta por la educación y la formación a lo largo de toda la vida, el aumento de la flexibilidad externa e interna, la reducción del coste relativo del trabajo poco cualificado, la renovación de las políticas de empleo y el fomento de "nuevos yacimientos de empleo" que permitirían crear tres millones de nuevos empleos en servicios de proximidad, mejora de las condiciones de vida y protección del medio ambiente ${ }^{19}$. En la Cumbre de Essen (1994) se fijaron dos principios: la búsqueda de una estrategia europea para el empleo y la fijación de prioridades indicativas para los Estados miembros.

Ahora bien, aunque las orientaciones y las prioridades se definan a nivel europeo, las políticas estructurales y sociales permanecen en el ámbito de competencia de los Estados y están separados de las políticas macroeconómicas. Entre 1994 y 1997, la coordinación a nivel europeo no ha modificado fundamentalmente las políticas de empleo nacionales, que han permanecido fuertemente diferenciadas ${ }^{20}$.

El Tratado de Amsterdam de 2 de octubre de 1997 (TA), a la vez que proponía el reforzamiento de los derechos sociales y ampliaba las competencias del Parlamento europeo en la adopción de las normas comunitarias, hizo de un "alto nivel de empleo" una prioridad de la UE (el art. 1.5 del TA que modifica el art. art. 2 en la versión consolidada-). y "una cuestión de interés comín", estableciendo como una de las acciones que competen a la Comunidad "el fomento de la coordinación entre las políticas en materia de empleo de los Estados miembros con vistas a aumentar su eficacia mediante el desarrollo de una estrategia coordinada para el empleo" (art. 3.c de la versión consolidada del TUE), marcando de esta forma un progreso sensible en relación con la Cumbre de Essen. El Tratado incluyó un título específico sobre empleo dentro del Tratado (Título VIII en la versión consolidada del Tratado Constitutivo de la Comunidad Europea). El nuevo art. 125 TCE vincula la estrategia para el empleo con la potenciación de "una mano de obra cualificada, formada y adaptable" y de "mercados laborales con capacidad de respuesta al cambio económico", es decir, una abierta llamada a la flexibilidad laboral.

En cuanto al contenido de esta política, es oportuno subrayar el cambio de óptica que se ha producido desde la Carta Social de Turín de 1961 al TA. La primera proclama el derecho al trabajo mediante una política de pleno empleo. Los arts. 125 y 126

19. Uno de los resultados de Essen fue la inversión por el Banco Europeo de Inversiones en los 3 años siguientes de más de 17 billones de Ptas., en proyectos decididos en esa Cumbre. especialmente en pequeñas y medianas empresas de alta tecnología.

20. J.C. Barbier, "La stratégie européenne pour l'emploi", Le 4 Pages du CEE, núm. 31, 1999. 
no hacen ninguna referencia al objetivo del pleno empleo, limitándose el art. 126 a señalar que los Estados miembros "considerarán el pleno empleo como un asunto de interés común". La distancia entre ambas formulaciones es enorme: la que media entre una fórmula típica del constitucionalismo social y otra la que se recoge el moderno paradigma del trabajo flexible.

En el Consejo Europeo extraordinario sobre el empleo de Luxemburgo (noviembre de 1997), reunidos por primera vez para discutir en exclusiva sobre el problema del empleo, los Jefes de Estado y de Gobierno afirmaron que "la cuestión del empleo se encuentra en el centro de las preocupaciones del ciudadano europeo" y que "debe hacerse todo lo posible para luchar contra el desempleo, cuyo nivel inaceptable amenaza la cohesión de nuestras sociedades"21. Este llamado "giro social" de Amsterdam-Luxemburgo se dio en el contexto de un agravamiento del desempleo desde 1992, uno de cuyos factores ha sido, de forma aparentemente paradójica, la política de restricciones presupuestarias y política monetaria restrictiva "impuestas" (sería más preciso decir autoimpuestas) a los Estados miembros para conseguir la Unión Económica y Monetaria ${ }^{22}$. Los Jefes y de Gobierno acordaron anticipar la eficacia del Título sobre el Empleo incorporado por el TA antes de que concluyera la ratificación del nuevo Tratado. Después de afirmar que el crecimiento económico no resolverá por si sólo las causas estructurales del paro, estableció como objetivos prioritarios la actuación contra la incapacidad de crear suficientes puestos de trabajo nuevos, la insuficiente e inadecuada cualificación de los trabajadores, la falta de adaptación a los nuevos modelos de organización del trabajo más flexibles y la desigualdad de oportunidades en el acceso al empleo.

A propuesta de la Comisión Europea, el Consejo de Ministros aprobó el 15 de diciembre de 1977 , que las políticas nacionales de empleo fueran revisadas para incorporar la aplicación de 19 Directrices, reagrupadas en cuatro pilares: mejora de la capacidad de inserción profesional, desarrollo del espíritu de empresa, estímulo de la capacidad de adaptación de las empresas y sus trabajadores y refuerzo de las políticas de igualdad de oportunidades. Como resultado de esa estrategia se debería alcanzar una tasa de empleo del $70 \%$ en el conjunto de la UE (el nivel de 1999 es del 60\%), es decir, un nivel que seguiría siendo inferior a los de EU y Japón $(74,3 \%$ y $75 \%$ respectivamente). En cinco años se pasaría al $65 \%$ con la creación de 12 millones de puestos de trabajo y la reducción al $7 \%$ del desempleo. Habiendo transcurrido ya tres años desde que fueron enunciados tales propósitos, parece altamente improbable que se vayan a cumplir estos objetivos.

21. Consejo Europeo Extraordinario de Luxemburgo. Conclusiones de la Presidencia (20-21 de noviembre de 1997).

22. Aspecto señalado en "Editorial" de RL, núm. 4, 1998, p. 1. 
En junio de 1999, el Consejo Europeo de Colonia ha relanzado el objetivo de un "Pacto Europeo para el Empleo", al que se le asigna el papel de ser la contrapartida del Pacto de Estabilidad de 1997. A la estrategia coordinada a favor del empleo (Cumbre de Luxemburgo) y a las reformas económicas estructurales (Cumbre de Cardiff, mayo de 1998) se agrega ahora un tercer eje, consistente en la coordinación de las políticas macroeconómicas, monetarias y presupuestarias, por una parte, y la evolución de los salarios por otra parte, instaurando un diálogo entre la Banca Central Europea (BCE), los actores sociales, la Comisión y el Consejo Europeos.

\section{Efectos y valoración de la política de empleo}

¿Cuáles son los efectos de la política europea de empleo?. Por una parte, al fijar objetivos comunes y establecer mecanismos de control de los objetivos y de los planes çoncretos diseñados por cada Estado, la política de empleo ha pasado a ser una política armonizadora en sentido genérico ${ }^{23}$, aunque esa política deja amplios márgenes a la diversidad de los mercados de trabajo estatales. Como mucho, el Consejo de Ministros puede dirigir recomendaciones particulares a cada Estado miembro. Es cierto, que el carácter no vinculante de las medidas de coordinación previstas, pudiera quedar relativizado si determinadas instituciones comunitarias, el Banco Europeo de Inversiones (BEI) y los Fondos Estructurales, especialmente el Fondo Social Europeo, asumiesen como un criterio importante al adoptar sus decisiones, el cumplimiento de las políticas de empleo ${ }^{24}$. La concepción de los planes de acción nacionales de empleo puede así estimular la conclusión de pactos sociales nacionales sobre las cuestiones ligadas al empleo en los países en los que las partes sociales están suficientemente implicadas en la negociación. A continuación, en la medida en que el proceso de coordinación utilizado es iterativo, las negociaciones entre países se pueden inscribir en una perspectiva de largo plazo y chocan menos con la exigencia de contrapartidas a corto plazo.

Las novedades más significativas de los Planes Nacionales de Empleo (PNA) consisten en la inclusión de problemáticas no abordadas anteriormente así como en la profundización de medidas ya experimentadas. Los PNA reconocen la importancia de la esfera local en la política de empleo, proponen un complejo equilibrio entre las medidas descentralizadoras y el mantenimiento de un marco común definido

23. F. Navarro Nieto, El tratamiento de la política de empleo en la Unión Europea, CES-Documentos, Madrid, 2000, págs. 17-18.

24. J. P. Landa Zapirain, "Las relaciones entre el Derecho del Trabajo y el Derecho del Empleo", REDT, n 98, 1999, pág. 832. 
nacionalmente y revalorizan la importancia de los servicios públicos de empleo para la aplicación de una estrategia de empleo $^{25}$. Sin embargo, la política europea de empleo presenta en la actualidad un cierto número de puntos débiles, algunos de los cuales eran reconocidos por la Comisión en su Comunicación al Consejo Europeo de Cardiff. Sólo dispone de medios financieros muy marginales: fundamentalmente la fracción de los fondos estructurales de orientación "recursos humanos", en especial el Fondo Social Europeo. De esa carencia de recursos se desprende el acento puesto en las evoluciones cualitativas de las políticas de empleo (activación de los gastos y evaluación). Las Directivas no tienen más que un valor indicativo y el examen de los PNA por la Comisión no prevé ninguna sanción por incumplimiento de lo establecido en los mismos, lo que contrasta significativamente con las políticas presupuestarias coordinadas en el marco del Plan de Estabilidad. La subordinación de las políticas de empleo a las políticas económica y monetaria limita su eficacia. En fin, la multiplicación de múltiples actores en la definición de la política europea de empleo convierte en particularmente complejo el proceso decisional, dejando a la Comisión un papel determinante en la decisión final. El PNA español para el año 2000, comparte buena parte de las deficiencias señaladas y no realiza una evaluación de los efectos de las acciones planteadas, especialmente desde el punto de vista cualitativo ${ }^{26}$.

Teniendo en cuenta la diversidad de políticas nacionales para el empleo, el mantenimiento de su carácter nacional, la separación práctica de la política de empleo de políticas macroeconómicas, adoptadas básicamente sobre consideraciones distintas de la política de fomento del pleno empleo -a pesar de la exigencia de compatibilizar la estrategia de fomento del pleno empleo con "las orientaciones generales de las políticas económicas de los Estados miembros y de la Comunidad", que prescribe el art. 126 TCE- y la debilidad de la coordinación a nivel europeo, limitan las posibilidades de acercamiento a corto plazo en las características y marcas del empleo de los Estados miembros. Sólo a largo plazo, el lugar acordado al empleo a nivel comunitario y el proceso iterativo puesto en marcha podría desembocar en una coordinación real, gracias al acercamiento progresivo de las percepciones nacionales y a una mayor implicación de los países en la definición de las líneas directrices. Por ahora, parece claro que, contrariamente a las afirmaciones optimistas de las instituciones comunitarias sobre los efectos de las políticas comunitarias de empleo ${ }^{27}$, la reducción del desempleo durante los años 1998 a 2000 se debe sobre todo al crecimiento económico.

25. M.C. Ortiz Lallana, "La Unión Europea y las políticas activas de empleo", RMTAS, núm. 17, 1999. págs. 19-21.

26. Lo que ha motivado una crítica de las organizaciones sindicales. Véase Anexo III al PNA 2000.

27. F. Navarro Nieto, El tratamiento de la política de empleo...cit., pág. 50. 
La política comunitaria de empleo se perfila como una política de "media intensidad": a diferencia de la política social que utiliza técnicas de armonización mediante Directivas, la nueva política comunitaria de empleo utiliza técnicas flexibles o blandas de regulación, producto de ámbitos de decisión política institucionalizados (Consejo de Ministros) o informales (diálogo social, expertos), o bien del ejercicio del poder ejecutivo sin someterse al marco constrictivo de una ley ${ }^{28}$.

Lo criticable, a mi entender, no es la coordinación de la política de empleo con las políticas presupuestarias, fiscales y otras, sino justamente la consideración secundaria del objetivo del empleo en esas políticas. El "alto nivel de empleo" que se propone como objetivo comunitario ${ }^{29}$, además de ser una concesión retórica en el contexto de las movilizaciones sociales europeas que se produjeron en Ámsterdam-Luxemburgo, significa un empleo que sea compatible con las políticas cle estabilidad monetaria, austeridad presupuestaria y competitividad máxima definidas para la Unión Económica y Monetaria.

Este diseño de constitución económica definida por los Tratados en la fase del postfordismo y la globalización se revela incompatible con los derechos sociales, al menos tal como fueron definidos por el constitucionalismo social ${ }^{30}$. Por otra parte, la apelación al pleno empleo como fórmula de solución universal de todos los problemas sociales está siendo utilizada por las autoridades comunitarias y estatales como pretexto para justificar los cortes a los gastos sociales, especialmente en materia de crítica a las políticas de jubilación anticipada y protección al desempleo ${ }^{31}$. A fin de conseguir el objetivo de la creación de empleo se debe aceptar la flexibilización de las regulaciones, la suavización de las constricciones y los costes para las empresas. En nombre de la "utilidad del empleo" se propone que la protección social "incentive" el empleo, a la vez que se insiste sobre la reducción de los costes indirectos del trabajo. En el caso español, es llamativo que a pesar de la duración y coste para las finanzas públicas y de la Seguridad Social de las diversas medidas (subvenciones, bonificaciones y reducciones de las cotizaciones sociales) de estímulo a la contratación, que yo sepa no se ha realizado una evaluación mínimamente rigurosa de su impacto sobre el empleo.

Otro aspecto preocupante es la pérdida del papel del Derecho del Trabajo y del Derecho Social en general en aspectos relacionados con la política de empleo. En cuanto al Derecho del Trabajo, porque el Derecho flexible de la política macroeconómica, cuyas

28. Cfr., J.P. Landa Zapirain, "Las relaciones entre el Derecho del Trabajo y el Derecho del Empleo". cit. pág. 812.

29. La Presidencia del Consejo Europeo celebrado en Lisboa, en marzo del 2000, declaraba que es necesario "restablecer las condiciones que favorezcan el pleno empleo" (punto 5 de las conclusiones).

30. Tal como apunta G. Maestro Buelga, "Constitución económica y derechos sociales en la Unión Europea", Revista de Derecho Comunitario, $\mathrm{n}^{\circ}$ 7, 2000, págs. 124 y 152.

31. Un ejemplo en el discurso del Presidente Aznar en el debate sobre "el estado de la nación" realizado el pasado mes de junio. 
medidas son escasamente vinculantes, soslaya el carácter y función garantista típica del Derecho del Trabajo. En nombre de la política de empleo se legitiman regulaciones del contrato de trabajo restrictivas de derechos ${ }^{32}$. En relación con el Derecho Social ${ }^{33}$, en la medida en que se asiste a una tendencia creciente a subordinar el derecho a las prestaciones de desempleo a las políticas activas de empleo, reduciendo la intensidad protectora de aquellas con el "pretexto" de impulsar a los parados a la búsqueda activa de empleo, a pesar de que muy frecuentemente no está en sus manos el acceso al mismo ${ }^{34}$. Como exponen Molina Navarrete y García Giménez en relación con la reforma laboral de marzo del 2001, el principio de favor laboratoris cede terreno frente al principio de protección de la capacidad del mercado para crear empleo (o para mantenerlo), aunque sea al precio de sacrificar parte de los derechos "adquiridos" por los trabajadores (insiders) en beneficio del acceso al empleo de los colectivos más vulnerables o, sin más, excluídos (outsiders) o en riesgo de estarlo ${ }^{35}$. Se podría añadir que el empleo no es un objetivo real de estas políticas, sino el pretexto de las mismas y que la verdadera finalidad no es asegurar empleo para los outsiders sino deteriorar los derechos laborales de todos ${ }^{36}$.

Es cierto que la política de empleo puede reforzarse a través de algunos aspectos de la política social en las que las instituciones comunitarias ostentan competencias armonizadoras: formas contractuales laborales y de trabajo flexible, normas sobre compatibilidad de la vida laboral y familiar, prohibiciones de discriminación por razón de sexo, lo que contriburía a relativizar el carácter subsidiario de esa política de empleo ${ }^{37}$. Sin embargo, los límites prácticos de las diversas normas armonizadoras -cuando existen-, reducen ese posible efecto sinérgico.

32. A. Baylos Grau, "Igualdad, uniformidad y diferencia en el derecho del trabajo”, $R D S, n^{\circ} 1,1998$, pág. 23.

33. La referencia al Derecho Social se formula para subrayar que, con independencia de la ubicación de las prestaciones de desempleo en el Derecho de la Seguridad Social o en el Derecho del Empleo, la cuestión decisiva es el mantenimiento de la suficiencia prestacional. Véase J.P. Landa Zapirain, "Las relaciones entre el Derecho del Trabajo y el Derecho del Empleo", cit., pág. págs. 827-8.

34. Esa orientación limitativa de las prestaciones de desempleo, con el pretexto de la "activación" de la política de empleo, se ha expresado en la reciente reforma realizada en Francia con motivo de la renovación de la Convención anual de la UNEDIC, mediante acuerdo de la organización empresarial MEDEF y una parte reducida del movimiento sindical (que representaban al $26 \%$ de los asalariados) y que, después de un rechazo inicial, ha sido validada por el Gobierno en octubre de 2000. El importante movimiento de parados y una parte del movimiento sindical se ha opuesto frontalmente.

35. C. Molina Navarrete y M. García Giménez, "Contratación laboral y política de empleo: primera fase de la nueva reforma del mercado de trabajo", RTSS-CEF, n² 217, 2001, pág. 9.

36. Como dice M. Monereo Pérez, "resulta paradójico que el proceso de integración europea que teóricamente debería servir para consolidar, al menos este modelo social..., esté siendo el principal ịnstrumento para disminuir derechos y poderes, tan costosamente conquistados por el movimiento obrero y ciudadano de todos y cada uno de los países europeos". Cfr., "Neoliberalismo, exclusión social y lucha de clases", Sistema, $\mathrm{n}^{\circ}$ 145-146, 2000, pág. 55.

37. F. Navarro Nieto, El tratamiento de la política de empleo...cit., pág. 60. 
Un reparto diferente de las ganancias de productividad: la Reducción del Tiempo de Trabajo (RTT)

Aunque el crecimiento económico de los últimos está permitiendo un relativo incremento del empleo, no se puede dejar en exclusiva al crecimiento la tarea de eliminación del desempleo. La persistente negativa de la mayoría de los gobiernos occidentales a sacar las conclusiones oportunas de los condicionantes ecológicos para el crecimiento económico contrasta con el amplio consenso en la comunidad científica sobre el gravísimo riesgo que supone la continuidad del actual modelo productivista para el equilibrio ecológico y su imposibilidad de generalización a escala planetaria. Este equilibrio se ve afectado de formas diversas: agotamiento de algunos recursos naturales no renovables, contaminaciones diversas, cambio climático... la jornada era la conquista de descanso y tiempo libre de los trabajadores. En las últimas décadas, esa tarea, sin desaparecer, cede la primacía al incremento del empleo: el papel fundamental que se le asigna es la contribución a la disminución del desempleo.

La RTT debe ir acompanada del mantenimiento de los salarios y de las condiciones de trabajo. Los economistas convencionales suelen señalar que, para que tenga éxito, la reducción de la jornada debe ir acompanada de incrementos de productividad por una mayor flexibilidad del tiempo de trabajo; que no aumente la masa salarial de las empresas, lo que implica por tanto que se produzca una compensación salarial total o parcial en términos mensuales; que se incremente la duración de los equipamientos y para ello que se desarrolle el trabajo en equipos.

Al obviar las condiciones sociales de su discurso, plantean procesos poco viables, no por incoherencia macroeconómica sino por irrealismo político. En efecto, mayoritariamente los asalariados no están dispuestos a aceptar voluntariamente la reducción de sus salarios y el empeoramiento de las condiciones de trabajo a cambio de una reducción de su presencia en la empresa y promesas de empleo futuras e inciertas. La intensificación del trabajo hace desconfiados a los asalariados -sobre todo a los de salarios más bajos- respecto a nuevas reorganizaciones del proceso productivo y en particular del tiempo de trabajo ${ }^{38}$.

Son poco realistas planteamientos, como el avanzado por $M$. Castells, que proponen una reducción equivalente y paralela del salario con la reducción de la jornada, que dice- sería compensada mediante un aumento del salario indirecto a través del desarrollo del consumo colectivo en salud, educación y cultura ${ }^{39}$. En efecto, la experiencia histórica

38. Aspectos señalados por T. Coutrot, "La réduction du temps de travail: mesure technocratique ou innovation conflictuelle?", en VV.AA, Appel des économistes pour sortir cle la pensée unique. Pour un nouveau plein emploi, Alternatives Economiques-Syros, Paris,1997, pág. 45.

39. M. Castells, "Futuro del Estado del Bienestar en la sociedad informacional", en S. Giner y S. Sarasa, Buen gobterno y politica social, Ariel, 1997, pág. 185. 
muestra que los países en losque se dan marcadas distribuciones desiguales de la renta de los factores primarios de producción no gozan de sistemas fiscales que corrijan significativamente las desigualdades básicas, sino que muy al contrario los sistemas fiscales más progresivos corresponden a sociedades con distribuciones de la renta más igualitarias (por ej. los países escandinavos). La significativa reducción del gasto público social en pensiones y desempleo, ayuda a las familias y educación que ha tenido lugar en España no permite alimentar este tipo de propuestas. El porcentaje sobre el PIB del gasto social ha disminuido desde el 24,7\% de 1993 hasta el 20,6\% del 2000, interrumpiéndose el proceso de acercamiento con la media europea en el gasto social, que es en la actualidad casi siete puntos superior (frente al 4,2\% de 1993) ${ }^{40}$.

A mi entender la RTT puede y debe jugar el papel central en el objetivo de un pleno empleo de calidad, haciendo del tiempo de trabajo la variable de ajuste de un desarrollo humano cualitativo y que tenga en cuenta las constricciones ambientales. La RTT con contrataciones proporcionales al tiempo liberado y el mantenimiento de los salarios supone efectivamente una reducción de la parte de los beneficios, pero ello no sería más que la compensación de su incremento y consiguiente reducción de la parte salarial que ha tenido lugar durante los últimos 20 años. Al establecer una afectación diferente de las ganancias de productividad, la RTT permite plantear el lugar del trabajo en la sociedad y se coloca en el centro de la transformación de las relaciones sociales. Debe permitir que el incremento de la productividad sirva para aligerar la dependencia humana del trabajo, a la vez que sea un poderoso motor en la creación de empleo.

El tiempo de trabajo determina a cuantos empleos dará lugar un cierto volumen de horas de trabajo y este segundo factor no está manteniendo una evolución que permita aprovechar las potencialidades del crecimiento para la creación de empleo. La variable tiempo de trabajo, que interviene en el volumen del empleo, ha sufrido un cambio en su tendencia histórica: la RTT se ha estancado en España durante los últimos años, durante algunos de los cuales se han llegado a producir incrementos en algunos sectores.

En la opción entre incremento salarial y RTT, hay que tener en cuenta que aunque técnicamente, es indiferente que el relanzamiento económico se deba a una elevación del salario por persona, o bien por el número de trabajadores empleados, no ocurre lo mismo desde el ángulo simbólico y político: la legitimación social es incomparable en un caso y en otro. Este aspecto incluye el efecto de arrastre de la RTT sobre otros países europeos ${ }^{41}$. Esta cuestión del marco europeo es clave para soslayar el problema de la competitividad de las empresas que se suele argüir como obstáculo para la RTT. El poderío económico de la UE y su grado de independencia en relación con el exterior, permite extender una RTT progresista y solidaria, sin que las empresas europeas tengan que sufrir graves problemas de

40. Véase el análisis que de ese proceso realiza V. Navarro, "El defícit social". El Paîs, 13-2-2001.

41. Vid. T. Coutrot, "La réduction du temps de travail..." cit., pág. 53. 
competitividad. Los efectos positivos de la RTT, en términos de creación de empleo, aumentarían con la generalización de la medida a otros países europeos.

La reciente experiencia francesa permite visualizar las posibilidades y condiciones de la RTT para la creación de empleo. A pesar de que la Ley Relativa a la Reclucción Negociada del Tiempo de Trabajo, de 15 de diciembre de 1999 (Aubry II), es una ley que favorece la distribución irregular de la jornada y otras medidas flexibilizadoras, que han resquebrajado buena parte del apoyo inicial de la población trabajadora, el balance provisional de la misma en términos de creación de empleo, se ha mostrado como más positivo que otras medidas de fomento del empleo ${ }^{12}$. Los 300000 empleos que finalmente se prevé que producirá la reducción de la jornada a 35 horas suponen un flagrante desmentido a las previsiones agoreras de la patronal francesa (el MEDEF) y de los círculos académicos neoliberales. Muestran que, además de contribuir a relajar la dependencia del trabajo para los asalariados ocupados, la reducción de la jornada se revela como una medida más eficaz para la creación de empleo que las basadas en là reducción del coste del trabajo, tales como la reducción de las cotizaciones sociales y/o de los salarios mínimos ${ }^{43}$.

\section{LAS RENTAS MíNIMAS DE INSERCión Y La POLITtCA DE FMPLFo}

\section{Algunas características de las rentas minimas y sus limites protectores}

El freno en la reducción del tiempo de trabajo y los límites e insuficiencias de las otras políticas de empleo están en la raíz de tasas de actividad y de empleo reducidas. Por otra parte el sistema de protección social no cubre adecuadamente las carencias de ingresos derivados de la falta de empleo. En efecto, la actual regulación de las prestaciones no contributivas de la Seguridad Social, además de establecer unas prestaciones de cuantía muy reducida, deja un enorme espacio para las situaciones de carencia de rentas por inactividad laboral, que no quedan cubiertas por las actuales

42. La reducción en dos horas de la jornada semanal que se ha producido entre 1997 y 2000 (de 38,9 a 36,9) habría debido suponer 700000 nuevos empleos (y 1,5 millones mediante la aplicación de las 35 horas a todo el sector privado), que según evaluaciones fiables se han visto limitadas a 160000 empleos. La diferencia entre las cifras teóricas y las reales se debe a la aceleración del incremento de la productividad resultado de las medidas flexibilizadoras. Las cifras están extraídas del interesante informe de la Fondation Copernic, Pour un plein emploi de qualité. Critique du social-libéralisme, à propos du rapport Pisani-Ferry, http://attac.org/fra/toil/doc/copernic.htm.

43. El coste de una creación de empleo debida a una reducción de cotizaciones sociales asciende a 105 000 francos, dos veces y media más cara que un empleo creado en el marco de la primera ley Aubry de RTT, de junio de 1998, cuyo coste era de 43000 francos. La segunda Ley Aubry ha elevado las subvenciones y suavizado drásticamente los compromisos de creación de empleo de la primera. Para un análisis conjunto de ambas leyes, véase $M$. de la Fuente, "Un comentario sobre la Ley "Aubry" II del tiempo de trabajo en Francia", Sistema, $n^{\circ} 157,2000$. Un balance cifrado de las diversas políticas de empleo se ha realizado por la Fondation Copernic, "Pour un plein emploi de qualité...". cit. 
prestaciones de desempleo, en la medida en que, salvo alguna excepción, éstas exigen actividad laboral previa y además son de duración limitada. Este terreno está parcialmente cubierto por las prestaciones, que con denominaciones diversas tales como Rentas Mínimas de Inserción (RMI), Ingresos Mínimo de Inserción u otras similares, han desarrollado las Comunidades Autónomas.

Según la concepción mayoritaria hasta ahora, las RMI no forman parte de la Seguridad Social sino de la Asistencia Social, componente complementario de la primera e integrante con ella de la Protección Social ${ }^{\text {t4 }}$. Una posición más reciente, aunque acepta que la actual regulación autonómica no permite asimilar a las RMI con la "asistencia social clásica" sino como una asistencia social externa, en cuanto organizada al margen del sistema de Seguridad Social, propone que debe configurarse como una técnica nueva dentro del sistema de Seguridad Social, en el contexto de un modelo más complejo y evolucionado de protección social pública. No sería incompatible el carácter asistencial de las prestaciones, en la medida en que su función sería garantizar la subsistencia en situaciones de necesidad, con su carácter simultáneo de prestación de Seguridad Social cuyos déficits de protección subsanarian. Estaríamos en presencia de una competencia compartida Estado-Comunidades Autónomas, siendo el título competencial para el Estado la inclusión de la asistencia social dentro del cuadro de prestaciones de la Seguridad Social por los arts. 55 y 56 de la Ley General de la Seguridad Social. De esta forma se permitiría garantizar prestaciones mínimas a todos los ciudadanos mejorables por las Comunidades Autónomas ${ }^{45}$.

Estas rentas mínimas se atribuyen, no en compensación de un daño o por la actualización de una contingencia o situación de necesidad, como ocurre en la regulación de nuestro sistema de Seguridad Social, sino directamente para proteger las situaciones de pobreza. Sin embargo, en la práctica totalidad de las Comunidades Autónomas el derecho a la renta mínima no se configura como un derecho subjetivo, ya que queda condicionada a la previsión presupuestaria anual correspondiente ${ }^{46}$.

La mayor parte de los programas autonómicos, inspirados en el modelo francés, han reunido el doble derecho a la renta y a la inserción en la misma figura. La cuantía de la prestación económica, además de ser reducida en general, varía en alto grado según las Comunidades Autónomas ${ }^{47}$, oscilando entre un suelo minimo constituido por el importe de las prestaciones no contributivas y un suelo máximo establecido en

44. M. Alarcón Caracuel, "Hacia el derecho de la protección social", en J. López López (Coord.), Seguridad Social y Protección Social: temas de actualidad, Marcial Pons, 1995, págs. 30-32.

45. En extenso sobre esta posición, J. L. Monereo Pérez y C. Molina Navarrete, El derecho a la renta de inserción. Estudio de su régimen juridico, Comares, Granada, 1999, págs.191-203.

46. Idem, pág. 245.

47. El gasto total ha venido siendo durante los años noventa de treinta mil millones anuales para toda España, con una cierta contención en los últimos años Cfr. L. Ayala Cañón, "Las rentas minimas ..." cit. p. 345. 
referencia al Salario Mínimo Interprofesional, utilizado corno criterio de referencia en varias normativas autonómicas para evitar que se produzca el efecto "desincentivador" de la búsqueda de trabajo ${ }^{+h}$. Su grado global de cobertura es muy bajo: sólo alcanza el $2,6 \%$ de los hogares que encuentran en situación de pobreza relativa y al $17.7 \%$ de los hogares que son demandas potenciales al reunir el requisito de que sus ingresos anuales no sobrepasen los baremos fijados en las normas autonómicas, cobertura que se reparte muy desigualmente ${ }^{* 4}$. Un límite importante es su atribución por "unidades de convivencia", con la atribución de cantidades bastante inferiores para el segundo y posteriores miembros.

El derecho a la inserción se formaliza mediante convenios o acuerdos, que tienen tres aspectos: la oportunidad para el beneficiario de acceder a una autonomía vital; el deber de las colectividades públicas en la promoción de los beneficiarios y la exigencia de la colectividad pública al beneficiario para que éste realice los esfuerzos necesarios, pactados previamente en el convenio, en orden a que consiga esa autonomía y abàndone su condición de asistido ${ }^{i \prime}$. En todo caso, los resultados de la política de inserción han sido escasos -en las Comuniclades Autónomas que han realizado un mayor esfuerzo, sólo un tercio de los beneficiarios habrían participado en actividades de inserción-, apuntándose como razones de ello los siguientes: heterogeneidad y escasa tradición de las iniciativas autonómicas en esta materia, las características de los beneficiarios (apartados en períodos más o menos amplios del mercado de trabajo), la escasa dotación presupuestaria para estos programas... "1.

La superación de esta situación exige sobrepasar el carácter puramente asistencial de las RMI, insertándolas en la política de empleo, reconociéndose así una utilidad social a la actividad realizada por los beneficiarios y otra expresión en nuevas relaciones de intercambio alternativas al modelo del clásico trabajo asalariado ${ }^{52}$.

\section{Un tímido ingreso del Estado en la inserción}

El espacio protector y de inserción laboral de las RMI se ha modificado como resultado de la aprobación por el art. 26 de la Ley de "Acompañamiento" para el año 2001, Ley 14/2000, de 29 de diciembre, que incluye la "renta de inserción", a regular

48. J. L. Monereo Pérez y C. Molina Navarrete, El derecho a la renta de inserción... cit., pág. 262.

49. El grado de cobertura se aproxima al $100 \%$ en la CAPV y en Navarra. en Madrid y Asturias es un tercio y en varias Comunidades Autónomas (Andalucía. Extremadura, valencia. etc.), no sobrepasa el 10\% de la demanda potencial. Cfr. L. Ayala Cañón, "Las rentas mínimas...", cit. p. 342 y ss.

50. Sobre el contenido $e$ instrumentación de la inserción, véase J. L. Monereo Pérez y $C$. Molina Navarrete, El derecho a la renta de inserción... cit., pág. 280 y ss.

51. L. Ayala Cañón, "Las rentas minimas...", cit. pág.. 344.

52. Cfr. J. L. Monereo Pérez y C. Molina Navarrete, El derecho a la renta de inserción... cit.. pảg. 430, que citan a X. Pretot. 
dentro de la acción protectora del desempleo y que tiene por destinatarios a "los desempleados con especiales necesidades económicas y dificultades para encontrar empleo". La Ley 14/2000, prevé asimismo implícitamente la utilización de los Convenios de Inserción, cuya suscripción por los desempleados parece plantearse como condición para la percepción de la "ayuda": "...que adquieran el compromiso de realizar actuaciones favorecedoras de su inserción laboral". Prevé asimismo implícitamente la utilización de los Convenios de Inserción, cuya suscripción por los desempleados parece plantearse como condición para la percepción de la "ayuda": "...que adquieran el compromiso de realizar actuaciones favorecedoras de su inserción laboral".

Esta disposición legal ha venido precedida por una norma de vigencia limitada al año 2000 y cuyo contenido puede prefigurar el desarrollo reglamentario al que se alude en el art. 26 de la Ley 14/2000, el RD 236/2000, de 18 de febrero, que desarrollaba una medida prevista en el Plan de Acción para el Empleo del Reino de España para 1999. Los rasgos más destacables del RD serían los siguientes: con la denominación de "renta activa de inserción", se establece una ayuda económica gestionada por el INEM y por las Comunidades Autónomas que tengan asumidas la gestión de políticas activas de empleo (DA $1^{2}$ ) y que se vincula a la realización de acciones en materia de políticas activas de empleo (art. 1); como requisitos para el acceso a la misma, se exige tener cumplida la edad de 45 años, ser desempleados inscritos en la oficina de empleo durante doce o más meses, haber extinguido la prestación contributiva o la asistencial de desempleo y tener responsabilidades familiares (art. 2) y suscribir un compromiso de desarrollo de actuaciones favorecedoras de su inserción laboral (art. 3); la cuantía de la renta queda fijada en el $75 \%$ del salario mínimo interprofesional (excluida la parte proporcional de pagas extraordinarias) para cuya percepción se establece un período de espera de tres meses desde la fecha de solicitud de incorporación al programa (art. 8). En cuanto al régimen de incompatibilidades, se puede señalar la compatibilidad con el trabajo a tiempo parcial (con deducción proporcional de la renta) y con los tres primeros meses de realización de un trabajo autónomo o de un trabajo por cuenta ajena que implique cambio en la localidad de residencia (art. 8.3.2 $2^{\circ}$ ). Esta renta de inserción ha tenido una aplicación muy reducida ${ }^{53}$. De la normativa expuesta resulta que

53. En el plazo concedido por el RD (tres meses a partir de su entrada en vigor el 11 de marzo de 2000 . es decir antes del 11 de junio, Disposición Final $1^{a}$ ) sólo se habian presentado 10 mil solicitudes, en lugar de las 90 mil previstas (Observatorio de Relaciones Industriales, $n^{\circ} 30,2000$, CES, p.3). Cuando se había finalizado de escribir este trabajo, se ha publicado el $R D$ 781/2001, de 6 de julio, por el que se aprueba un programa para el año 2001, en desarrollo de la Ley 14/2001, que tras una muy rápida lectura no me parece que supone modificaciones importantes en relación con el RD 236/2000. Si amplia el número de beneficiarios al no mantener el requisito de tener responsabilidades familiares. 
aunque la cuantía económica de esta renta de inserción es superior a la generalidad de las rentas mínimas autonómicas, su ámbito es más reduciclo, por cuanto que además de la edad mínima de 45 años, sólo abarca a las personas que hayan sido perceptoras de la prestación contributiva y/o cle del subsidio asistencial. Por otra parte, comparte una nota asistencialista con las RMI, al condicionar la financiación de la parte del programa de la renta activa de inserción a la existencia de crédito presupuestario disponible (DA $4^{a}$ ).

\section{El ejemplo de la Comunidad Autónoma del País Vasco (CAPV)}

Una tentativa de superar, al menos parcialmente los límites de estas rentas de inserción, la constituía la llamada Iniciativa Legislativa Popular para una Carta de los Derechos Sociales, que tras haber recogido 82.062 firmas - frente a las 30000 exigidas- en la Comunidad Autónoma Vasca y haber sido admiticla a trámite, se ha tramitado como Proyecto de Ley en el Parlamento Vasco. Esta Carta plantea, entre otras medidas, la atribución de una renta básica equivalente al salario mínimo interprofesional a todas aquellas personas que queriendo trabajar no puedan acceder a un puesto de trabajo, la reducción del tiempo de trabajo a 35 horas en el sector privado mediante la negociación colectiva promovida por el Gobierno vasco y a 32 horas en el sector público $^{54}$, la eliminación de las horas extraordinarias ${ }^{55}$ y la anticipación de la edad de jubilación a los sesenta años.

Sobre la base de su discusión, en un clima de intenso debate político y social, se ha aprobado en el Parlamento Vasco la Ley 10/2000, de 27 de diciembre, de Carta de Derechos Sociales, cuyo el objeto es "proclamar en el ámbito de la CAPV una Carta de Derechos Sociales que posibilite a todos los ciudadanos el acceso al mercado de trabajo y les garantice una renta básica para que puedan ejercer sus derechos de ciudadanía" (art. 1). El art. 3 enumera como "derechos sociales básicos" los de protección social suficiente, la protección de la salud, la educación de calidad, una vivienda digna y adecuada y un medio ambiente protegido.

La creación de empleo se plantea por la Ley como la principal solución de los problemas derivados del paro, que no limitan sólo a la carencia de rentas sino a las dificultades para la integración social y ejercicio de la plena ciudadanía (Exposición de Motivos y art. 4).. En relación con el tiempo de trabajo, aunque se le asigna una función de promoción del empleo (art. 2.3), se propone la adopción de medi-

54. Según el Informe elaborado por los promotores de la Iniciativa Legislativa Popular a la Ponencia del Parlamento Vasco, la aplicación de las 32 horas a la administración pública vasca, supondria la creación de 6 313 puestos de trabajo. Cfr., Iniciativa Legislativa Popular, Dictamen de Conclusiones, Bilbao, 2000, pág. 11.

55. En ídem se estima que la supresión de las horas extraordinarias en los sectores público y privado implicaría crear entre 18000 y 20000 puestos de trabajo. 
das no sólo de reducción sino también de "reordenación" y de "flexibilidad", que tal como hemos expuesto no favorecen la creación de empleo mediante la RTT y la eliminación de las horas extraordinarias se asigna a los acuerdos "entre agentes sociales". En relación con el tiempo de trabajo, aunque se le asigna una función de promoción del empleo (art. 2.3), se propone la adopción de medidas no sólo de reducción sino también de "reordenación" y de "flexibilidad", que tal como hemos expuesto no están inspiradas en favorecer la creación de empleo sino en incrementar la productividad mediante una gestión más flexible de la mano de obra. Para el personal al servicio de la Administración de la CAPV la Ley prevé la aplicación de las 35 horas, la suscripción de contratos de sustitución y relevo y la supresión de las horas extra ${ }^{56}$.

La regulación más detallada y directamente aplicable de la Ley es la concerniente a la "Renta Básica", siendo sobre la misma sobre la que se concentró el grueso de la discusión política y sindical. La cuantía fijada es "la necesaria para garantizar unos ingresos del $75 \%$ del Salario Mínimo Interprofesional en doce mensualidades para una sola persona", es decir 63.105 ptas. mensuales. La fórmula aprobada supone un incremento de unas diez mil ptas. mensuales sobre las cantidades en vigor (provenientes de la Ley 12/1998, de 22 de mayo, contra la Exclusión Social). A pesar de esta mejora, la nueva ley ha sido duramente criticada por los promotores de la Iniciativa Legislativa Popular y por el conjunto de los sindicatos, que han entendido que se había producido un "fraude" a las personas que firmaron la Iniciativa. Las declaraciones a los medios de comunicación realizadas por los partidos políticos que apoyaron la Ley insistían, como motivación fundamental para rechazar la solicitud de la Iniciativa Popular de equiparación de la Renta Básica con el SMI la desincentivación para el trabajo que supondría y sólo de forma secundaria argumentaban problemas presupuestarios $^{57}$.

La Renta Básica de la nueva Ley no cubre el objetivo que se asigna a la misma de "eliminar las situaciones de pobreza". Conforme al criterio de pobreza en vigor en la UE, se considera en situación de "precariedad económica" a toda persona o unidad familiar cuyos ingresos estén comprendidos entre el $35 \%$ y el $50 \%$ de la media y en "pobreza moderada" a las que se sitúen en el intervalo del $25 \%$ al $35 \%$ por ciento de

56. Ya con anterioridad a la promulgación de la Ley 10/2000, el 28 de junio de 2000, en la Mesa General de Negociación de la Administración de la CAPV, los sindicatos ELA, CC.OO, UGT y LAB suscribieron un Acuerdo con la Administración Pública de la CAPV que establece las 35 horas semanales y un máximo anual de 1592 horas, con efectos al 1 de enero de 2000.

57. Es significativo que uno de los motivos más importantes por las que el PNV y EA no han llegado a un acuerdo para la constitución del Gobierno de la CAPV con Ezker Batua (Izquierda Unida del País Vasco) ha sido el rechazo a aceptar esa equiparación de la Renta Básica con el SMI y consiguiente modificación de la ley 10/2000. 
la renta media ${ }^{58}$. Pues bien, si la renta interior bruta per cápita de la CAPV era en 1998 de 2.529 .970 ptas. ${ }^{59}$, el límite de la precariedad sería de 1.264 .985 ptas. y el de pobreza moderada en 885.490 ptas. cifra notablemente superior a la cantidad de 757260 ptas. que para las personas individuales resulta de la Renta Básica para el año 2001 (63. 105 Ptas. por doce meses). Se subraya que la renta per cápita se habrá incrementado aproximadamente un 10\% en los tres años transcurridos desde 1998. Las diferencias aumentan para las unidades de convivencia de varios miembros, ya que la Ley incrementa en sólo un 25\% del SMI para la segunda persona y un 10\% más para cada persona a partir de la tercera, con el límite del $125 \%$ por unidad de convivencia, salvo casos excepcionales establecidos reglamentariamente por el Gobierno vasco (art. 7). Es decir, que el percibo de la Renta Básica no elimina las situaciones de pobreza moderada, sino que solamente alcanzaría a prevenir la llamada pobreza grave, la que afecta a quienes posean rentas de entre el 15 y el $20 \%$ de la media.

La Renta Básica se configura como una prestación complementaria al establecer la compatibilidàd de la misma con todo tipo de recursos y prestaciones sociales de contenido económico que pudieran corresponder al titular o a cualquiera de los miembros de su unidad económica de convivencia independiente, siempre y cuando sus recursos no sobrepasen la cuantía mensual de la renta Básica ${ }^{(0)}$, por lo que como la generalidad de las Rentas Mínimas autonómicas se configura como una prestación de carácter diferencial ${ }^{6 \prime}$, en el sentido que la cuantía efectivamente percibida por sus beneficiarios será solamente la resultante de restar a la cantidad fijada en la norma, teniendo en cuenta los complementos asignados a los diferentes miembros de la unidad de convivencia, los recursos percibidos por el beneficiario.

No obstante, desde el año 2000, en una regulación extremadamente compleja la normativa vasca se ha planteado el estimulo al empleo de los titulares de la Renta Básica, excluyendo del cómputo de los recursos a determinados porcentajes de ingresos procedentes del trabajo por cuenta propia o ajena del titular, de los demás miembros de su unidad de convivencia o de las demás personas, que conforme a la normativa, pudieran beneficiarse de las prestaciones ${ }^{62}$. En la medida en que la Renta Básica incrementada con todo o parte de los ingresos de actividad no puede sobrepasar un determinado nivel, supone una incitación al

58. Tal como se recoge en el informe del CES, La pobreza y la exclusión en España: propuestas de actuación en el marco del plan nacional para la inclusión social. CES, 2001, pág. 10.

59. Fundación BBVA, Renta Nacional de España y su distribución provincial, Fundación BBVA, 2000, pág. 92.

60. Arts. 2.2 y 3.3.a) del RD 1989/1999, de 20 de abril, regulador del Ingreso Mínimo de Inserción.

61. En los términos utilizados por J. L. Monereo Pérez y C. Molina Navarrete, El derecho a la renta de inserción... cit., pág. 263.

62. La primera regulación de la exclusión parcial de los ingresos se realizó por la Orden de 2-2-2000, que ha sido sustituida por la Orden de 14-2-2001, que adapta las cuantías a la nueva Ley 10/2001. 
trabajo en empleos atípicos, -ocasionales, a tiempo parcial, temporales-, que resulta muy problemática ${ }^{6,3}$.

La normativa de la CAPV estimula la incorporación de personas desempleadas a las empresas de economia social, con el objetivo de superar lo que se califica como bajo nivel de empleabilidad que presentan. Así, el Decreto 182/2000, de 19 de septiembre, en vigor hasta el año 2003 inclusive, prevé ayudas a las entidades públicas o privadas sin ánimo de lucro que se detallan (art. 2) que realicen un amplio espectro de acciones que tienen por objeto proporcionar a las personas en situación o riesgo de exclusión social, mediante un proceso formativo combinado con una práctica laboral través de contratos de trabajo de carácter temporal, a tiempo parcial, en empleos de utilidad social (art. 1). El Decreto 305/2000, de 26 de diciembre, regula la calificación de las empresas de inserción y el procedimiento de acceso a las mismas por parte de las personas con especiales dificultades de acceso al mercado laboral ordinario, regulación que tiene la pretensión de "conciliar la lógica empresarial con la lógica de la inserción social, ofreciendo una oportunidad de participar en actividades productivas, en el mercado de trabajo,..., adaptada a sus posibilidades y capacidad reales en sus circunstancias sociales"6it. El aseguramiento simultáneo de su finalidad de inserción social y de eficacia económica se garantiza estableciendo un mínimo del $40 \%$ de trabajadores en proceso de inserción respecto al total de la plantilla y un máximo del 75\%. Se entiende por trabajadores en proceso de inserción no sólo a las personas desempleadas que puedan acceder a un Convenio de Inserción, en los términos previstos en la Ley 12/1998 (en la actualidad hay que entender la remisión a la Ley 10/2000), es decir, los titulares del Ingreso Mínimo de Inserción (ahora Renta Básica) y otros miembros de su unidad familiar cuando en los mismos concurran otras causas de exclusión distintas de las de naturaleza económica, sino también a cualquier persona que, a juicio de los servicios sociales, requiera de una intervención específica para la inserción.

\section{REFIEXIONES FINALES}

En el conjunto de la Unión Europea, y también en España, la preocupación por la desincentivación al trabajo que supuestamente entrañaría la existencia de prestaciones generosas de desempleo, ha traído consigo una reducción de estas prestaciones, acompañada de una "activación" de las políticas de empleo, que a veces se concreta en amenazas de privación de las prestaciones a los parados que no muestren sufi-

63. Sobre la problemática que plantea la acumulación de salarios y prestaciones sociales, véase $\mathbf{M - T}$, Joint-Lamber. "Le cumul salaires/allocations représente-t-il une voie d'avenir?", Droit Social, n' 6, 2000, págs. 632-636.

64. Cfr. J. L. Monereo Pérez y C. Molina Navarrete, El derecho a la renta de inserciōn... cit., pä́g. 432. 
ciente intensidad en la búsqueda de empleo o su disponibilidad en aceptar los empleos que se les propongan.

El riesgo de las trampas del paro sólo existe en aquellos contratos que unen a su precariedad extrema, especialmente los de tiempo parcial involuntario, remuneraciones muy reducidas. Las soluciones deben venir de la supresión de las regulaciones que permiten esa precariedad y una elevación general de los salarios mínimos, lo que no tiene porqué implicar consecuencias negativas para el empleo.

Mientras no se aplique una reducción generalizada e importante del tiempo de trabajo que al permitir la creación masiva de empleo suponga la erradicación de los núcleos esenciales de la exclusión social, se debe proceder a una elevación generalizada de las prestaciones sociales, tales como las rentas mínimas de inserción, que garanticen el derecho a una vida digna.

La "inserción por lo económico" que está siendo realizada por las empresas de inserción está alcanzando una muy importante dimensión en Europa, hasta el punto que se ha solicitado una actuación coordinada por parte de la Unión Europea ${ }^{65}$. Estas empresas deben ser apoyadas más activamente por las políticas públicas, a todos los niveles territoriales. Deben formar parte del desarrollo de un sector no mercantil, público o asociativo, que impida la monopolización de la actividad económica por grupos cada vez más poderosos y concentrados, sometidos a la única lógica del beneficio exigido por los accionistas.

65. Ídem, pág. 433 y sigs. 